\title{
Despindo Anna Karenina
}

\author{
Despindo Anna Karenina
}

\section{Undressing Anna Karenina}

\author{
Amilcar Almeida Bezerra ${ }^{1}$
}

Ana Paula Celso de Miranda ${ }^{2}$

Palavras chave:

Moda

Consumo

Cinema

Narrativa

\section{Resumo:}

O objetivo desse trabalho é contribuir com a compreensão da dinâmica de consumo no contemporâneo com a análise dos processos midiáticos como fonte de (re/des)construção da identidade de marca a partir da apropriação dos significados na narrativa dos personagens, proporcionando ao espectador uma projeção por idealização. Neste estudo foi utilizado o filme Anna Karenina, vencedor do Oscar de melhor figurino em 2013, para apresentar uma abordagem metodológica para análise do vestuário como instrumento da narrativa cinematográfica e como esta pode ser apropriada pela narrativa das marcas utilizadas no processo de adensamento de seus sentidos. 


\section{Resumen:}

El objetivo de este trabajo es contribuir a la comprensión de la dinámica del consumo en contemporáneo con el análisis de los procesos de comunicación como fuente de (re / de) construcción de la identidad de marca a través de la apropiación de los significados de los personajes de la narración, dando al espectador una proyección por la idealización. En este estúdio, la película Anna Karenina, ganador del Oscar al mejor diseño de vestuario en 2013, se utilizó para presentar una propuesta metodológica para el análisis de la ropa como un instrumento de la narración cinematográfica y cómo esto podría ser apropiado para la narración de las marcas que se utilizan en el proceso de densificación de los sentidos.

Palabras clave:

Moda

Consumo

Cinema

Narrativa

\section{Keywords:}

Fashion

Consumption

Cinema

Narrative

\section{Abstract:}

The aim of this work is to contribute to understanding the dynamics of consumption in contemporary with the analysis of media processes as a source of (re / de) construction of brand identity through the appropriation of the meanings of the characters in the narrative, giving the viewer a projection by idealization. In this study, the film Anna Karenina, winner of the Oscar for best costume design in 2013, was used to present a methodological approach for the analysis of clothing as an instrument of cinematic storytelling and how this might be appropriate for the narrative of the marks used in the densification process of their significations. 


\section{Despindo Anna Karenina}

\section{Introdução}

O figurino no Cinema é composto por todas as roupas e os acessórios dos personagens auxiliando a definir local, tempo e atmosfera da cena bem como as características dos personagens (COSTA, 2002). O objetivo deste estudo é contribuir com a análise do figurino como elemento da narrativa no cinema, ao mesmo tempo em que acrescenta, para a melhor compreensão dos elementos constitutivos de um processo de construção, além dos aspectos do vestuário, os movimentos e planos de cena e o contexto simbólico onde o mesmo está inserido.

\section{A moda segundo o modelo psicológico}

O indivíduo possui tendência psicológica à imitação. Esta proporciona a satisfação de não estar sozinho em suas ações. Ao imitar, ele não só transfere a atividade criativa, mas também a responsabilidade sobre a ação dele para o outro. A necessidade de imitação vem da necessidade de similaridade. Sob esta dimensão conclui-se que moda é a imitação de um modelo estabelecido que satisfaça a demanda por adaptação social, diferenciação e desejo de mudar, sendo baseada pela adoção por um ou mais grupos sociais. (SIMMEL, 1904)

"Deste duplo movimento de imitação e de distinção nasce a mutabilidade da moda" (LIPOVETSKY, 1989, p. 53).

Tal processo de busca da identidade dentro do contexto social que indica a necessidade de consumo da moda não é de todo maléfico. De certa forma, a moda cumpre o papel de compreensão do próprio eu, e é instrumento de prazer, culto da fantasia e da novidade: simplesmente é divertido estar na moda.

"A moda é um discurso livre e um dos privilégios, se não um dos prazeres, de um mundo livre" (LURIE, 1997, p.50).

A lógica é a diferença individual e a inovação estética, ou promoção da identidade pessoal e legitimação da expressão individual. Ou seja, diferenciar para singularizar, ao mesmo tempo em que não rompe com os padrões da sociedade. Esta parece ser a interpretação de LIPOVETSKY (1989, p. 39), quando diz:

Mas a moda não foi somente um palco de apreciação do espetáculo dos outros; desencadeou, ao mesmo tempo, um investimento de si, uma auto-observação estética sem nenhuma precedente. A moda tem ligação com o prazer de ver, mas também com o prazer de ser visto, de exibir-se ao olhar do outro [...] As variações incessantes da moda e o código da elegância convidam ao estudo de si mesmo, à adaptação a si das novidades, às preocupações com o próprio traje.

O modelo psicológico de moda mostra como muitos fatores psicológicos ajudam a explicar por que pessoas são motivadas para estar na moda. Estes incluem conformidade social, busca da variedade, criatividade pessoal e atração sexual. Estes consumidores têm necessidade de ser únicos, querem ser diferentes, mas não tão diferentes assim que percam a sua identidade social. A moda é dependente do contexto: o mesmo produto pode ser interpretado diferentemente por diferentes consumidores e em diferentes situações (SOLOMON, 1996).

Os modelos psicológicos são: 


\section{Modelo centrado no individualismo}

Nos anos 80 a moda começa a se configurar enquanto busca da individualidade, a importância de ser "especial" é enfatizada pela comunicação de moda. Este aspecto explica porque a moda se torna obsoleta, o que ocorre pela saturação social acompanhada por esta superestimulação dos sentidos.

O estilo de vestir é assinatura, reação contra a sociedade de massa. A individualidade é expressa amplamente pela forma como se veste (DICHTER, 1985).

\section{Modelo centrado na conformidade}

Pressões sociais para a conformidade podem influenciar dramaticamente a escolha de estilos. Esta pressão ocorre principalmente pela aprovação social do grupo no qual o indivíduo quer ser aceito.

Influenciar consumidores para adotar ou rejeitar produtos depende do significado social destes e da sua relação com os grupos de referência (ENGLIS et al., 1994). A palavra chave para grupos de referência parece ser influência pessoal.

\section{Modelo de motivação única}

Pessoas comparam a si próprias com outras procurando por similaridades e diferenças para formar sua auto-identidade (SPROLES, 1985).

O uso proeminente da moda é com o objetivo de desenvolver senso de identidade pessoal. Consumidores usam a moda para representar tipos sociais específicos e formar senso de filiação ou dissociação com a construção de identidade social por eles idealizada (THOMPSON, 1996).

\section{Porque Anna Karenina?}

Para entender o cinema e seus personagens como modelos idealizados para provocar o desejo antropofágico de consumir esses produtos com o objetivo de consumir o outro num ritual mágico de transformação escolhemos o filme Anna Karenina por: ter sido o vencedor do Oscar de melhor figurino 2013, apresentar personagem central mitificada por várias versões desta obra literária e utilizar na sua narrativa de marca com alto grau simbólico proporcionando um dialogo de contágio entre a personagem e a marca e vice-versa.

Adaptação do romance homônimo do escritor russo León Tolstói (1828-1910) originalmente publicado em 1878, o filme Anna Karenina, dirigido pelo inglês Joe Wright, foi o vencedor do Oscar de melhor figurino no ano de 2013. O enredo da película, ambientado na Rússia da década de 1870 , tem como eixo central o conflituoso triângulo amoroso entre a protagonista Anna Karenina, o marido, Alexey Karenin, um alto funcionário da burocracia russa, e o Conde Alexey Vronski, um jovem oficial da cavalaria. Na medida em que o caso extraconjugal de Karenina e Vronski torna-se mais evidente aos olhos da sociedade da época, a protagonista passa a sofrer as consequências do rigoroso julgamento moral imposto pelo meio aristocrático ao qual também pertence.

Anna Karenina é o terceiro longa-metragem do diretor Joe Wright estrelado pela atriz Keira Knightley. Antes, haviam trabalhado juntos em Orgulho e preconceito (2005) e Desejo e reparação (2007), ambos adaptações de obras literárias. $O$ primeiro filme, baseado no romance lançado em 1813 da escritora britânica Jane Austen, conta a história de Elizabeth, uma garota do campo, cuja personalidade invulgar desperta o interesse de um jovem aristocrata inglês em desposá-la. A diferença de 
classe e os preconceitos sociais dela resultantes funcionam na narrativa como obstáculos a serem contornados pelo par central da trama para chegarem à concretização do seu amor. A produção obteve quatro indicações ao Oscar: melhor atriz para Keira Knightley, melhor trilha sonora para Dario Marianelli, melhor direção de arte para Sarah Greenwood e melhor figurino para Jacqueline Durran. Na ocasião, contudo, a produção não levou nenhuma estatueta.

Em 2007, para a produção de Desejo e Reparação, Joe Wright reuniu novamente Marianelli, Greenwood e Durran, que mais uma vez foram indicados ao Oscar de melhor trilha sonora, melhor direção de arte e melhor figurino, respectivamente. Estrelado novamente por Keira Knightley, trata-se de outro drama romântico, mas, nesse caso, as tensões são desencadeadas por uma intriga familiar. Desta feita, Marianelli levaria para casa a estatueta pela trilha sonora. O filme ainda concorreria em quatro categorias naquele ano: melhor filme, meIhor roteiro adaptado, melhor fotografia e melhor atriz coadjuvante (Saoirse Ronan), totalizando sete indicações.

A mesma equipe de indicados ao Oscar foi mantida na produção de Anna Karenina. Jacqueline Durran, pela terceira vez indicada ao Oscar de melhor figurino, seria a premiada na ocasião. Ela já havia sido agraciada com o BAFTA Awards, premiação da indústria cinematográfica britânica, pelo seu trabalho com o figurino do filme Vera Drake (2005), de Mike Leigh. Depois de duas indicações, Durran chegaria ao Oscar 2013 como favorito ao prêmio, graças ao meticuloso trabalho realizado em Anna Karenina.

\section{Vestindo Anna Karenina}

Em seu clássico estudo sobre a reprodutibilidade técnica das obras de arte, Walter Benjamin (1936) já atentava para a natureza essencialmente "coletiva" do cinema. A magnitude da obra cinematográfica exige a mobilização de um grande volume de recursos materiais e simbólicos para sua realização e, consequentemente, uma difusão em massa para compensar os recursos mobilizados na produção. Assim, o filme acaba sendo uma "criação da coletividade", na medida em que dela depende, necessariamente, para se viabilizar. Pressupondo então o filme como obra coletiva, entendemos que o conjunto de relações estabelecidas entre os indivíduos e instituições que participaram de sua concepção e produção interage de forma intensa com o imaginário do público. Além disso, a numerosa equipe de produção de um filme acumula um considerável capital simbólico que corresponde a um complexo arcabouço técnico e teórico desenvolvido por meio da sistematização e da sedimentação de conhecimentos oriundos de diversas instituições do campo da arte e da mídia, dentre as quais as instituições de moda. Neste artigo, observamos como parte desse capital simbólico é agenciado de modo a compor a construção da narrativa fílmica por meio da concepção do figurino da produção Anna Karenina.

Diferente dos trabalhos anteriores do diretor Joe Wright, nos quais predominava uma visão mais naturalista e simplificada do figurino histórico, Anna Karenina traz uma proposta conceitual exuberante e estilizada, mantendo uma coerência com o caráter teatral das interpretações e dos cenários do filme. A narrativa, por exemplo, se desenvolve num palco de teatro, ao qual somos apresentados nas cenas iniciais, e a personagem principal surge pela primeira vez num camarim, em companhia de sua criada. Tais escolhas sugerem, desde o início do filme, a intenção de recriar com certo grau de liberdade o texto de Tolstói.

Para Wright, cada filme que dirige é, em si, uma coreografia, noção levada ao 
limite em Anna Karenina. Segundo ele próprio, a produção foi concebida como um "balé com palavras". Fiel a esse conceito, contratou para a equipe de produção o coreógrafo experimental Sidi Larbi Cherkaoui, responsável por coreografar tanto as cenas de dança, quanto a movimentação dos atores ao longo de todo o filme.

Conforme relata Jacqueline Durran, ela recebeu como briefing do diretor Joe Wright a missão de, com foco nas siIhuetas típicas da época, simplificar a superfície da indumentária aristocrática da década de 1870 com inspiração na couture da década de 1950. Wright enfatizou ainda que Durran, ao conceber as peças, deveria ter em mente uma atmosfera provinciana como ponto de partida. Esse conceito traduziria a situação periférica da Rússia em relação à Europa naquela época, bem como o modo de vida das elites aristocráticas locais, cujo provincianismo se evidencia nos julgamentos morais, na inveja e na hipocrisia observados na postura dos personagens ao longo da narrativa. Havia também a preocupação do diretor em dotar cada personagem de um figurino que representasse de forma particular não apenas características da personalidade, mas também o papel por ele exercido no desenvolvimento do enredo. A preocupação de situar a personalidade de Anna Karenina em contraste com os valores do seu meio social, por exemplo, levou Durran a materializar essa diferença em várias situações, nas quais o figurino da protagonista se destaca de uma certa homogeneidade conscientemente aplicada a outros figurinos da cena.

Em superproduções desta magnitude há sempre uma estrutura visual planejada para o filme, cuja tônica é comumente atribuída pelo diretor, mas acaba sendo também produto de uma complexa interação envolvendo os mais diversos setores da produção que trabalham de forma coordenada. No caso de Anna Karenina,
Durran destaca a importância do diálogo com Wright e com a protagonista Keira Knightley, a quem atribui um forte senso de estilo, para o sucesso da empreitada.

Ciente do seu papel no conjunto da equipe, a figurinista define Joe Wright como um diretor com forte identidade visual, e que costuma dar instruções precisas nesse aspecto da produção. Sua principal função como figurinista seria então concretizar a visão do diretor. Contudo, revela que várias decisões são tomadas em conjunto com Wright e Knightley, como, por exemplo, a opção pela parceria com a griffe Chanel, que cedeu diversas joias para compor cenas do filme.

\section{Propondo uma perspectiva de análise}

Ao empreendermos a análise simbólica do figurino no filme Anna Karenina, partimos da premissa que a indumentária desempenha uma função significativa na construção da narrativa cinematográfica. Entendemos, portanto, que todas as escolhas feitas no processo de produção do figurino, da criação à confecção, obedecem a propósitos específicos que residem na dimensão simbólica do material analisado. No caso do cinema, a dimensão simbólica do figurino se encontra, de variadas formas, subordinada à narrativa do filme, assim como todos os seus outros aspectos estéticos (cenários, sequências, planos, etc...).

Como obra coletiva moderna por excelência (BENJAMIN, 1994), o cinema vem produzindo e reproduzindo uma mitologia contemporânea em profunda relação com o imaginário do público. Conforme professa Umberto Eco (1964), profissionais como cineastas, designers e publicitários produzem, tendo como matéria-prima o imaginário popular, imagens míticas que vão se instalar na sensibilidade das massas ${ }^{3}$. 
Produtores de obras coletivas como o Cinema, portanto, mobilizam mitos contemporâneos num esquema de co-participação com o público espectador/ consumidor.

Assim, adotamos como pressuposto que, no planejamento do figurino, há uma preocupação dos produtores em agenciar conscientemente referências mitológicas midiaticamente consagradas para inseri-las como elementos visuais do figurino de maneira a fortalecer os laços simbólicos da estética das peças com os significados que habitam a narrativa em questão.

Por isso propomos uma análise semiológica de matriz barthesiana separada em três níveis: o denotativo, o conotativo e o mítico. Nos apoiamos ainda na metodologia proposta por Gemma Penn, que aplica os conceitos de interpretação de signos a imagens paradas, na análise de figurino proposta por Maciel \& Miranda (2009) e no modelo descritivo e interpretativo de planos e movimentos de câmera proposto por Jullier e Marie (2007).

Embora saibamos que, na prática, os processos de significação aconteçam simultaneamente em vários níveis de profundidade e consciência, consideramos pertinente, a título de análise, sistematizar a divisão acima proposta apenas com o propósito de tornar mais evidente a complexidade tanto dos processos de criação quanto de interpretação das imagens.

\section{Ato 1 - Denotação}

A denotação reside no nível descritivo, o mais elementar do significado. Trata-se de uma espécie de "inventário" das imagens coletadas. Quanto mais apurado o olhar descritivo, mais sólidos os alicerces para o trabalho de interpretação.
Neste estudo de caso, a descrição elege como focos principais as ações dos personagens, a indumentária, os cenários, os enquadramentos e os movimentos de câmera no contexto da narrativa.

O traje deve ser dissecado em suas formas (modelagem, comprimento, volume), cores, materiais de confecção e composição das peças. O encadeamento das ações das personagens deve ser descrito de modo a fazer sentido no contexto da narrativa, dedicando especial atenção à postura e ao gestual como dimensões munidas de significado. Planos e movimentos de câmera devem também ser observados, descritos e entendidos como elementos de linguagem funcionais para a ambientação e o decorrer da história. Para Jullier e Marie (2007), os planos podem ser classificados conforme sua extensão, composição e intenção narrativa em: ponto-de-vista, close up, plano médio e plano geral. A disposição e o movimento dos corpos nos planos fixos (centralizado, mais à esquerda ou à direita), a profundidade do plano, o foco, a câmera alta ou baixa, os movimentos laterais, verticais, a aproximação e o distanciamento são alguns dos recursos utilizados para compor a narrativa cinematográfica, e devem ser descritos no conjunto de suas relações com a ação dos personagens e os elementos estéticos dos trajes e cenários apresentados. Esse conjunto compõe o sintagma, ou seja, a mensagem a ser comunicada.

\section{Ato 2 - Conotação}

A conotação se refere a um nível mais alto de significado. Nessa etapa, é necessário mapear os efeitos de sentido, ou seja, as "associações trazidas à mente" (PENN, 2000) suscitadas pelas relações, justaposições, correspondências e contrastes entre os elementos observados no nível anterior. 
Aqui é necessário dispor de certos conhecimentos culturais para empreender uma interpretação do sintagma. "Barthes chama esse conhecimentos de léxicos. Ele define um léxico como 'uma porção do plano simbólico (da linguagem) que corresponde a um conjunto de práticas e técnicas'. Ele pode ser prático, nacional, cultural ou estético e pode ser classificado."

Quando se fala em conotação, vislumbra-se um movimento de abstração que parte da concretude do significante para os significados a ele associados. Neste caso, o léxico necessário para a interpretação dos significados da mensagem em questão são conhecimentos produzidos e disseminados por instituições específicas do campo da arte, da cultura da mídia e do universo da moda. É neste nível que nos permitimos avaliar a utilização dos recursos simbólicos em consonância com as intenções narrativas a cada cena do filme analisado.

Aqui, o objetivo é evidenciar quais os conhecimentos culturais necessários para empreender uma leitura que inclua a resposta às indagações de "como" e "por que" a mensagem foi construída daquela forma. Partimos da premissa que todos os elementos estéticos que compõem a mensagem cinematográfica foram conscientemente escolhidos e organizados segundo o léxico de profissionais da área com o propósito de produzir efeitos de sentido no contexto da narrativa. Assim, a concepção dos figurinos, por exemplo, cumpre um importante papel na expressão da personalidade das personagens e de sua função em cada situação retratada, bem como na narrativa como um todo.

\section{Ato 3 - Mito}

O Mito é o símbolo da transcendência. Numa perspectiva barthesiana, trata-se de uma representação que consagra e naturaliza uma dada hierarquia de valores éticos e/ou estéticos e a sintetiza em narrativas e/ou imagens. Como vimos, a cultura da mídia, na qual se inclui o cinema, é produtora e reprodutora de mitos contemporâneos em constante interação com o imaginário do público. Tais referências simbólicas consagradas pela cultura da mídia podem ser percebidas na construção dos personagens por meio da estética dos figurinos. Nesta etapa, enfatizamos os aspectos metalinguísticos da construção do significado para entender como, na construção da mensagem, são feitas alusões a mitos contemporâneos, sobretudo nos campos do cinema e da moda. E que essas alusões tem como objetivo produzir efeitos de sentido sobre os esquemas interpretativos de um determinado público.

\section{Despindo Anna Karenina}

Entender o figurino, o movimento de câmera e a iluminação em cena como elementos do dialogo entre os personagens e a audiência é condição necessária para que a compreensão entre a narrativa e o público aconteça. É o simbolismo interativo referente à interação entre seres humanos que define ou interpreta cada ação dos outros ao invés de meramente reagir a elas (BLUMER, 1969; FORSYTHE et. al., 1985). Esta comunicação é mediada através do uso de símbolos ou pela interpretação do significado dos atos dos indivíduos.

Significa-se sempre, seja ao outro, seja a si mesmo. (LEVI-STRAUSS, 1970, p.212)

Para o entendimento do figurino como elemento da narrativa da personagem no filme foram escolhidas duas cenas que encerram as duas grandes transformações e definem o papel da personagem 
na trama e a posiciona em relação a si mesma e aos outros personagens.

\section{Cena do Baile - sedução aos $26 \mathrm{~m} 40$ s}

Convidada pela jovem cunhada Kitty, Anna Karenina, acompanhada do irmão, comparece a um grande baile. Lá encontra mais uma vez o conde Vronsky, com quem já havia se deparado na estação. $O$ conde, até então provável pretendente de Kitty, não consegue esconder sua preferência por Karenina. A tensão entre as três personagens é o fio condutor da cena.

\section{Ato 1 - Denotação}

Kitty usa um modelo branco com saia e ombros à mostra, aparentado a um vestido de noiva (ver figura 2). Anna Karenina usa um vestido preto, bastante decotado e ostenta plumas, colar de diamantes em forma de flores e cabelo com um leve toque de desarrumação. Tem ombros à mostra, decote nas costas, saia no estilo 1870 atrás, mas com tule na frente e sem a cauda (ver figura 1). Conde Vronsky usa traje branco assemelhado a uniforme militar.

Depois de um plano médio em que a câmera frontal recua lentamente para acompanhar a entrada de Kitty no salão do baile, a câmera gira sobre o próprio eixo e desvela, num plano geral, o salão repleto de casais dançando harmonicamente em movimentos coreografados. As cores dos figurinos femininos, todos aparentados, variam em alguns tons pastéis, à exceção das protagonistas da cena. Nas sequências que se sucedem, predominam planos-médios e closes, com a câmera acompanhando os movimentos da dança. Por instantes, enquanto Vronsky dança com Karenina, os demais casais ficam paralisados, estabelecendo um nítido contraste. No clímax da cena,
Vronsky ergue Karenina num passo de dança, e quando ela volta a pisar no solo, o ambiente fica envolto na penumbra e uma luz branca ilumina sua dança com Vronsky, no centro de um salão escuro e vazio (ver figura 3 ).

\section{Ato 2 - Conotação}

Nesta cena, o interesse mútuo despertado no encontro casual entre Karenina e Vronsky, que havia acontecido na estação, se transforma em paixão. Toda a cena e movimentos traduzem sedução e trazem indícios das conseqüências que seus atos vão trazer para ela e para os outros. O figurino de Anna Karenina fala de sua personalidade e do seu papel na trama. Colocado num contraste em relação aos demais personagens, ele alude ao impacto que ela vai ter na vida dos que a cercam e na sua própria, no momento em que a paixão é revelada.

O preto de Karenina já sugere o destino da personagem no desenrolar da narrativa, a partir dessa cena-chave. $\mathrm{Na}$ cena em que ambos dançam sozinhos no salão, se estabelece o contraponto entre o branco (Vronsky) e o preto (Karenina).

O visual de Anna Karenina tem seu apelo conotativo maximizado também em contraponto com o de Kitty. Luxo versus simplicidade; sedução versus inocência; Experiência versus juventude (ver figura 2). Reforça aqui o aspecto da construção do eu transferido para a narrativa do filme, no qual pessoas comparam a si próprias com outras procurando por similaridades e diferenças para formar sua autoidentidade (SPROLES, 1985).

A cena se encerra com Karenina diante do espelho, no qual se vislumbra e se ouve a chegada de um trem imaginário que prenuncia o seu destino trágico (ver figura 5). 

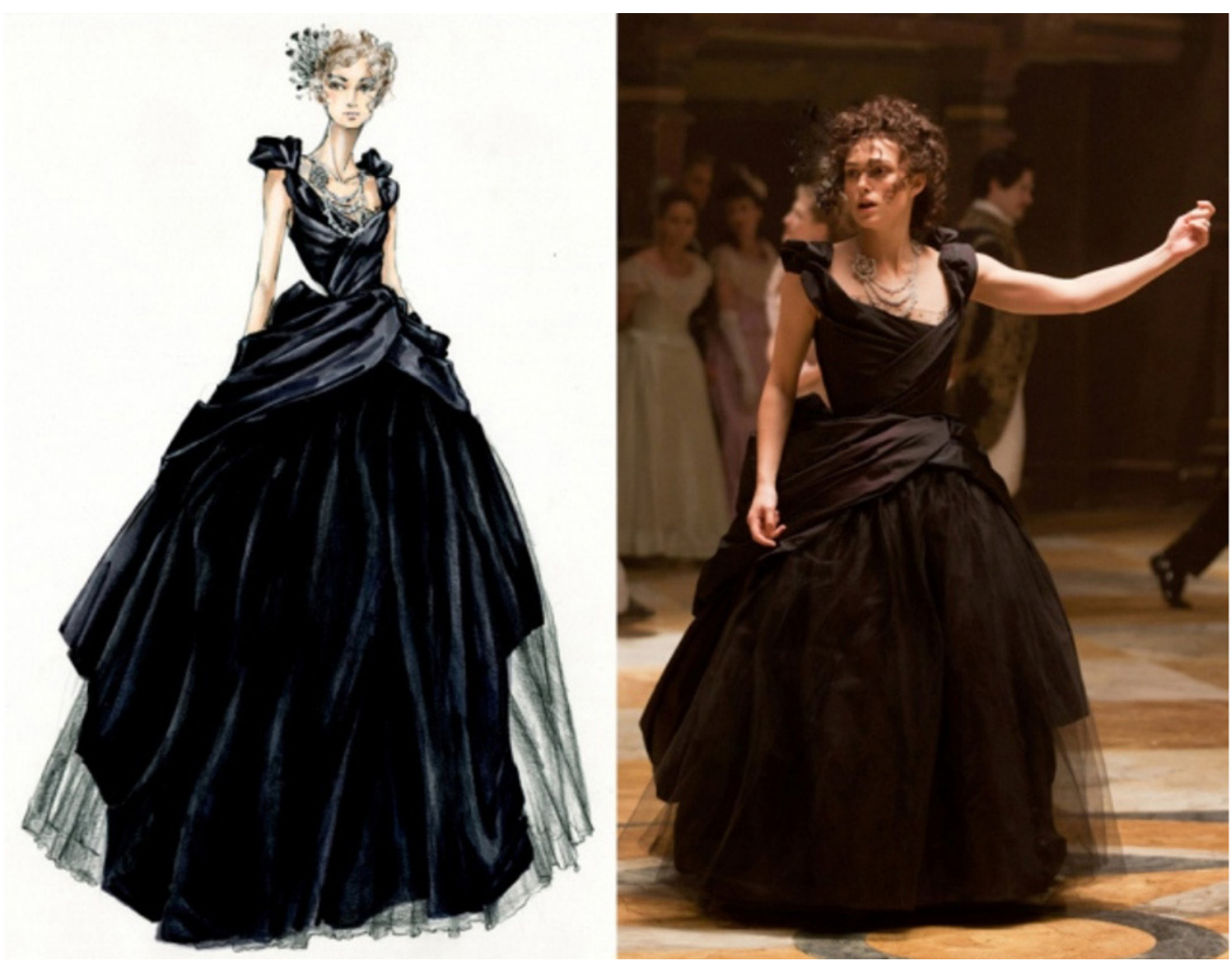

Figura 1: Croqui e look na cena do baile

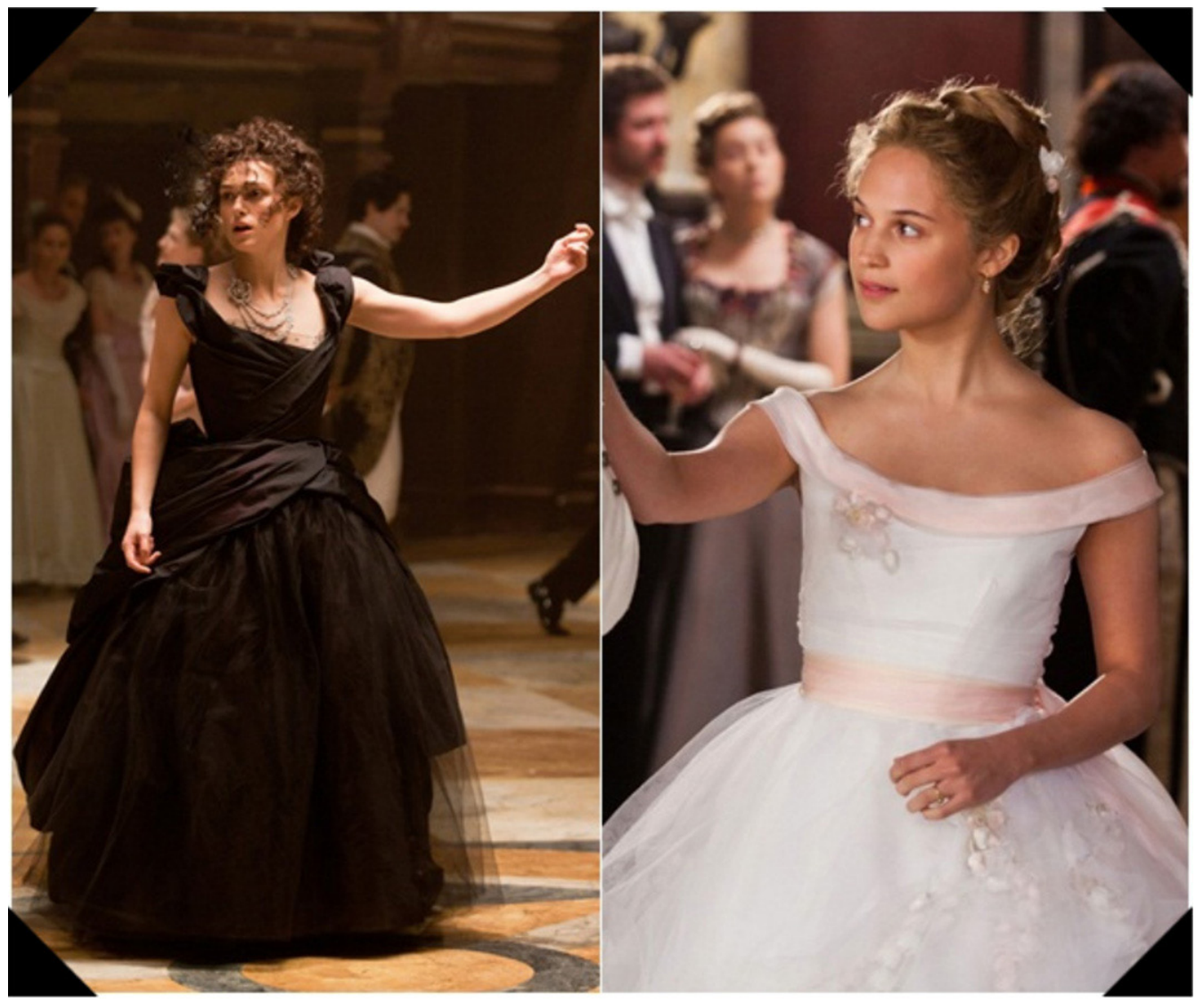

Figura 2: Look de Anna Karenina em contraponto com o look de Kitty 


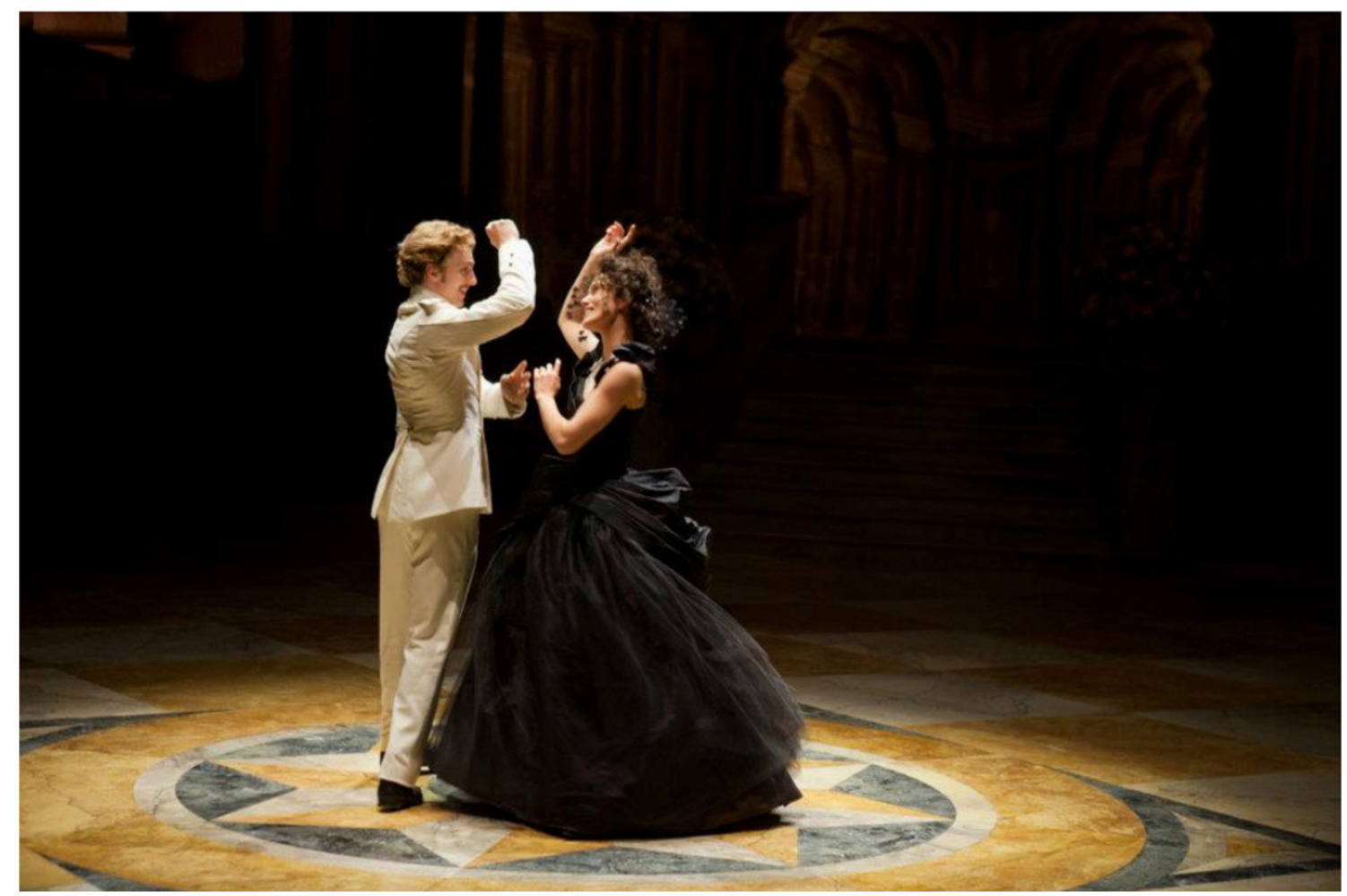

Figura 3: Cena de dança com Ana Karenina e Vronsky

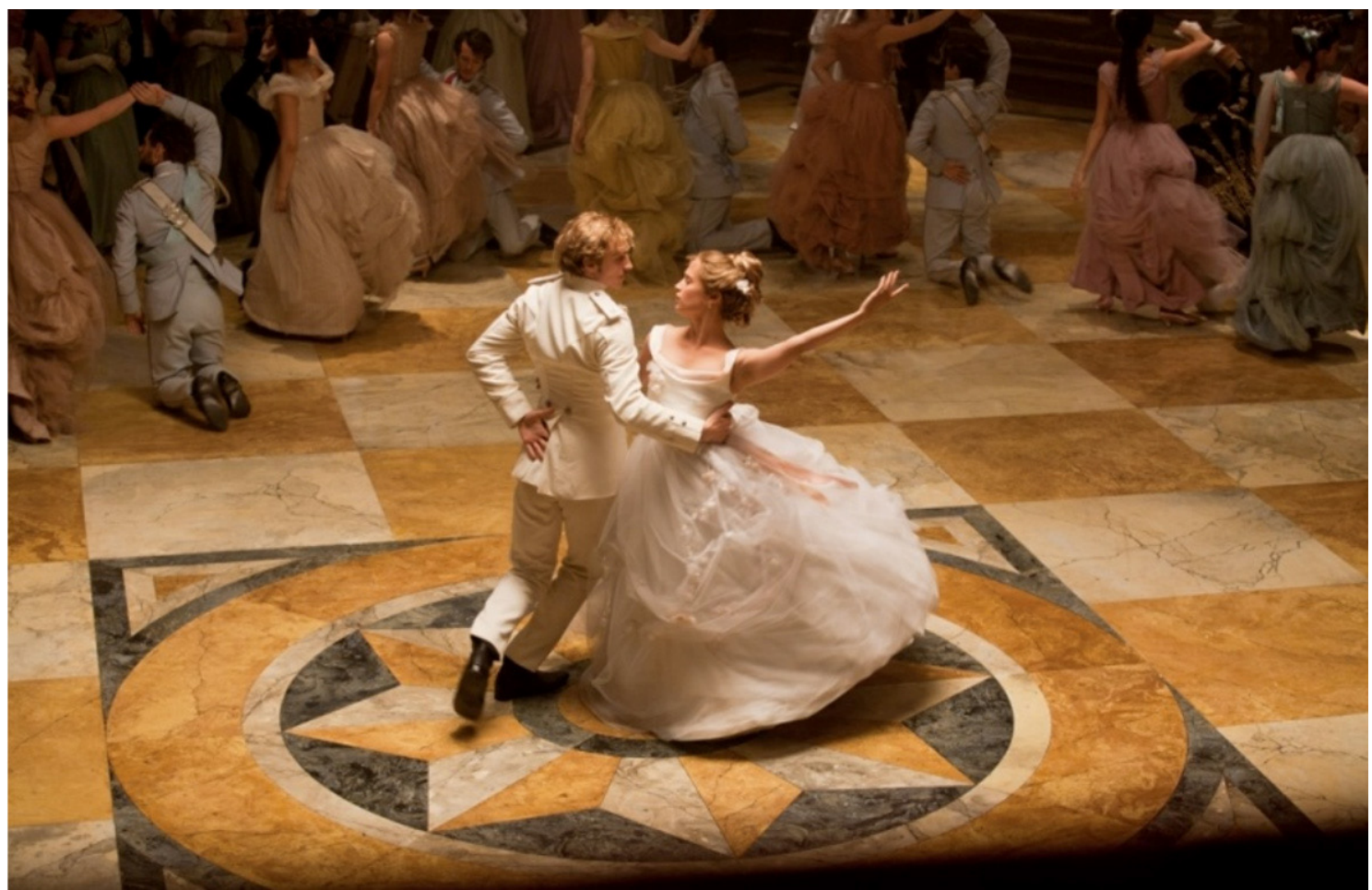

Figura 4: Cena de dança com Kitty e Vronsky 


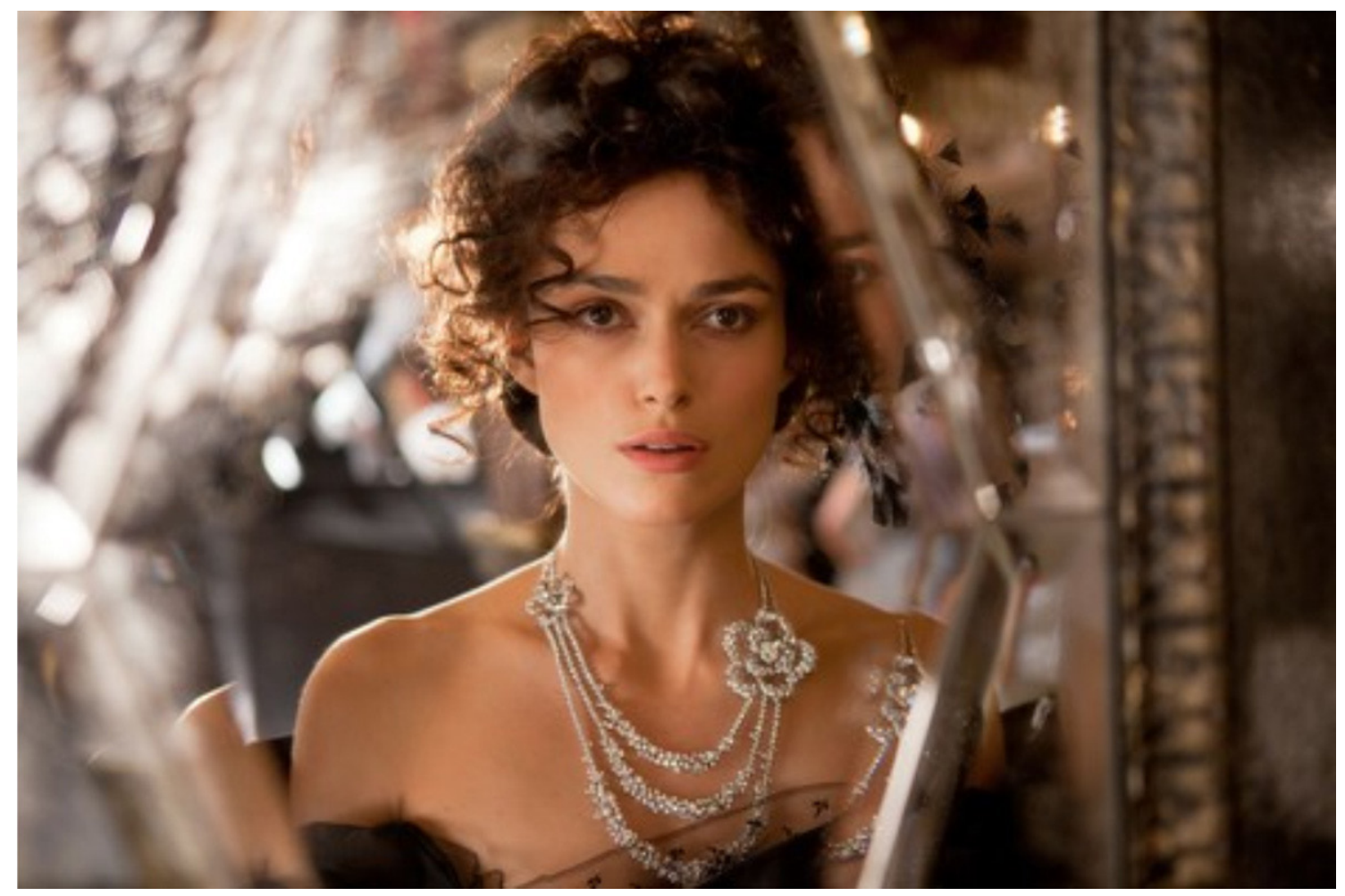

Figura 5: Plano final da cena do baile e detalhe do colar Chanel

\section{Cena da Ópera - humilhação aos 102m}

Depois de muito insistir, Karenina é levada por Vronsky à Ópera. A essa altura do enredo, o relacionamento entre os dois já havia se tornado público, e Karenina sente na pele todo o desprezo da sociedade aristocrática local.

\section{Ato 1 - Denotação}

Karenina vai à ópera de vestido longo, branco, brilhante, com ombros à mostra. $\mathrm{O}$ modelo se parece com um vestido de noiva. A câmera alta se afasta e reduz o tamanho da personagem, sugerindo de modo sutil o pouco que ela pode fazer diante da situação que estará prestes a enfrentar. Cabelos e diamantes iguais ao do baile, mas as plumas estão mais discretas e o vestido branco ilumina o ambiente reforçando o sentido de autenticidade. Os diamantes brilham. Tudo mais é fosco. As personagens presentes no recinto, tratam Karenina com frieza e desprezo.

Vronsky chega após Karenina, e conversa com familiares na platéia, enquanto a protagonista está acomodada numa frisa, ao lado de uma amiga. Ao final da cena, uma senhora sentada numa frisa vizinha começa, em voz alta, a direcionar impropérios contra Anna Karenina. Neste momento, a câmera se aproxima até chegar ao rosto da protagonista em close-up. Uma luz branca cai sobre seu rosto, fazendo cintilar os diamantes dos brincos que usa. Em seguida, a câmera começa a se afastar da protagonista e nos permite vislumbrar aos poucos, em plano geral, uma platéia imobilizada que a observa fixamente. Há um facho de luz sobre Anna Karenina, seu vestido branco e suas joias brilham em contraste 
com o ambiente ao seu redor, mergulhado nas sombras (ver figura 8). A cena se encerra com mais um close-up em Karenina, enquanto uma lágrima escorre do seu olho direito.

\section{Ato 2 - Conotação}

Nesta cena acontece a reviravolta na vida da personagem. Acostuma- da a ser admirada no seu meio social, ela passa por um momento de rejeição. A sociedade representada por aqueles que estão assistindo a ópera deixa clara sua reprovação ao comportamento de Anna Karenina que até então acredita que pode ter tudo: o amor romântico e o convívio em sociedade. O branco, a luz e o brilho instilam a pureza da personagem diante da maldade das pessoas que irá vitimá-la.

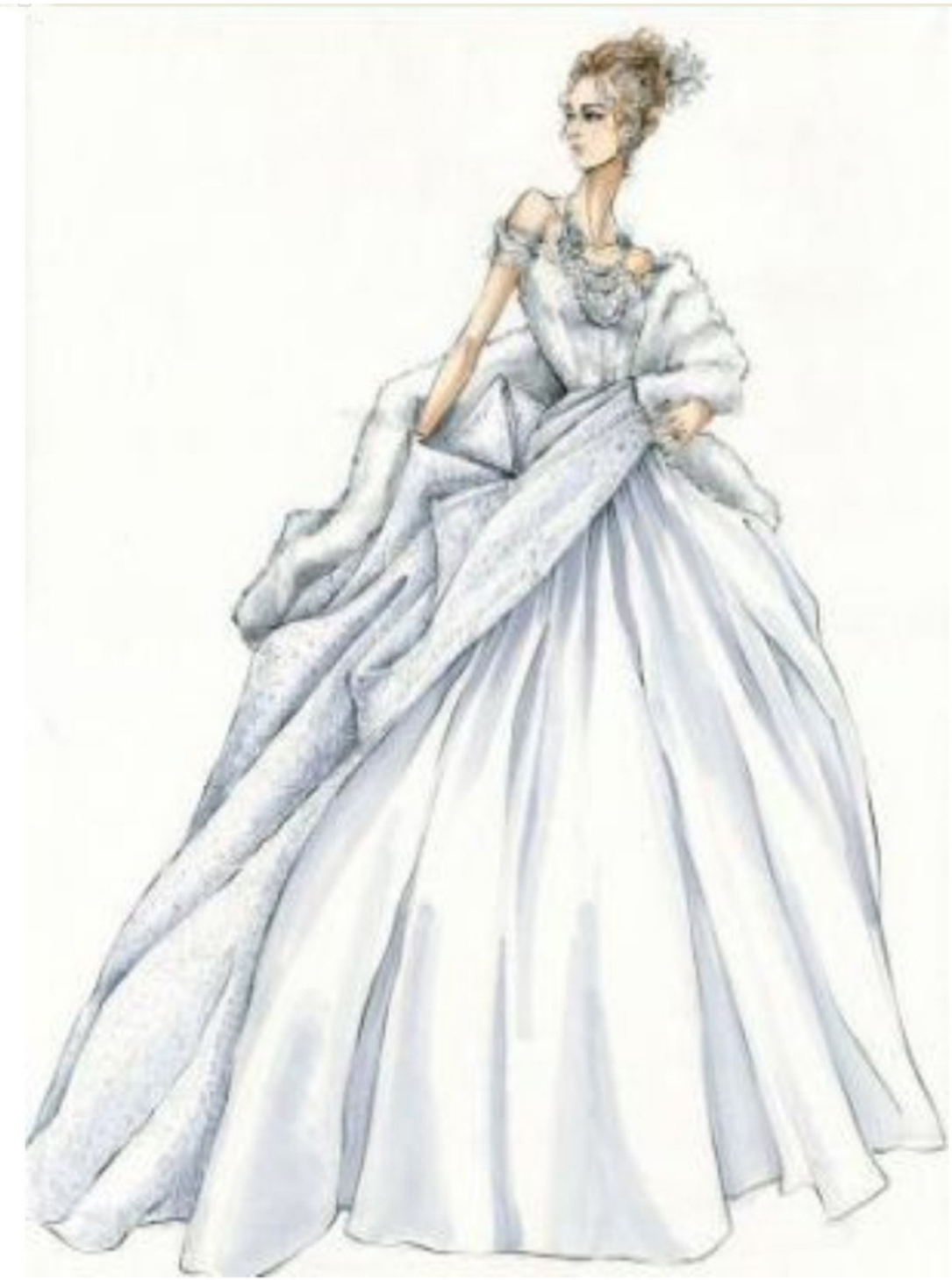

Figura 6: croqui do look de Anna Karenina na cena da ópera. Modelo Dior e Jóias Chanel. 


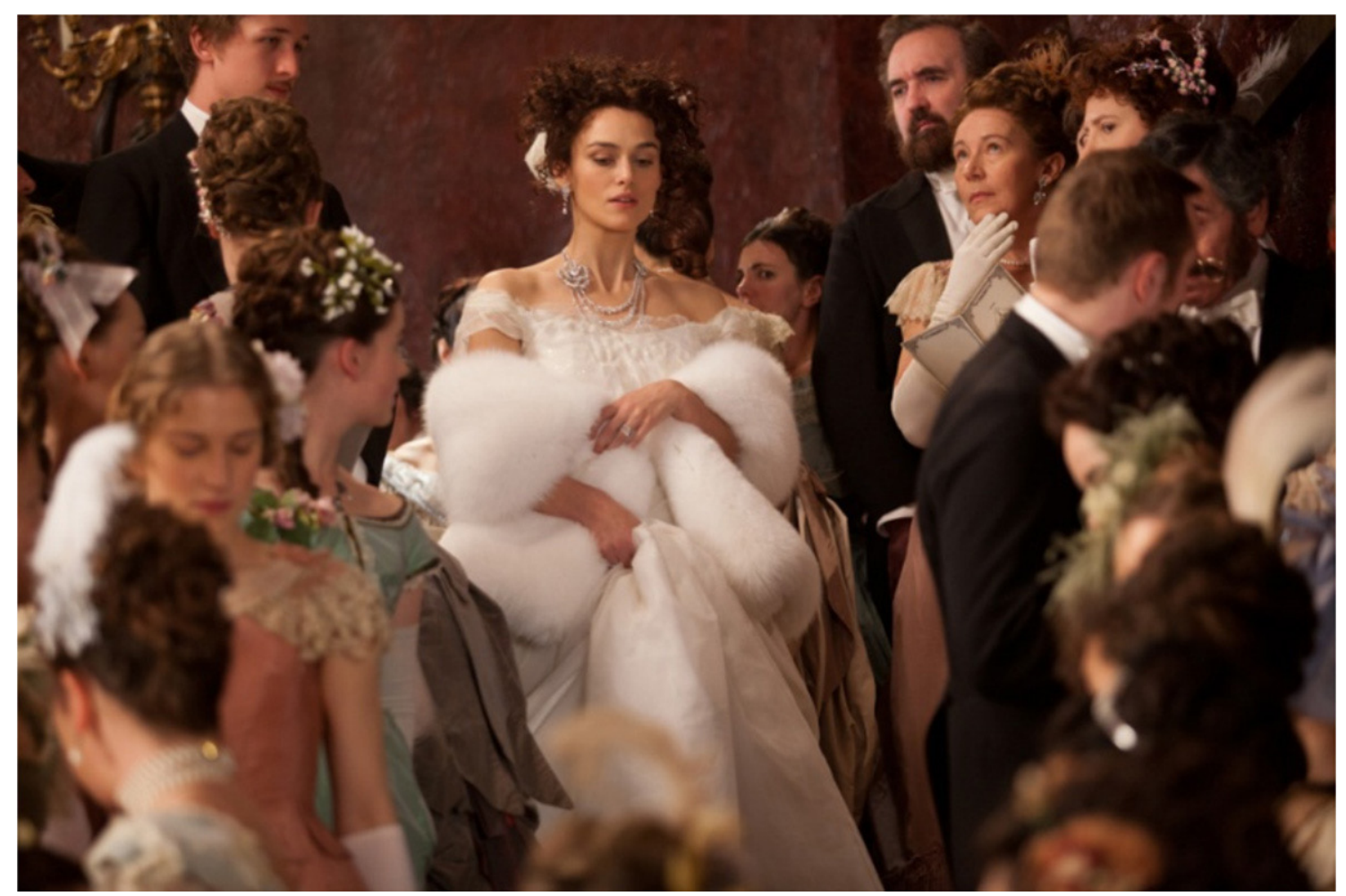

Figura 7: Look na cena da ópera

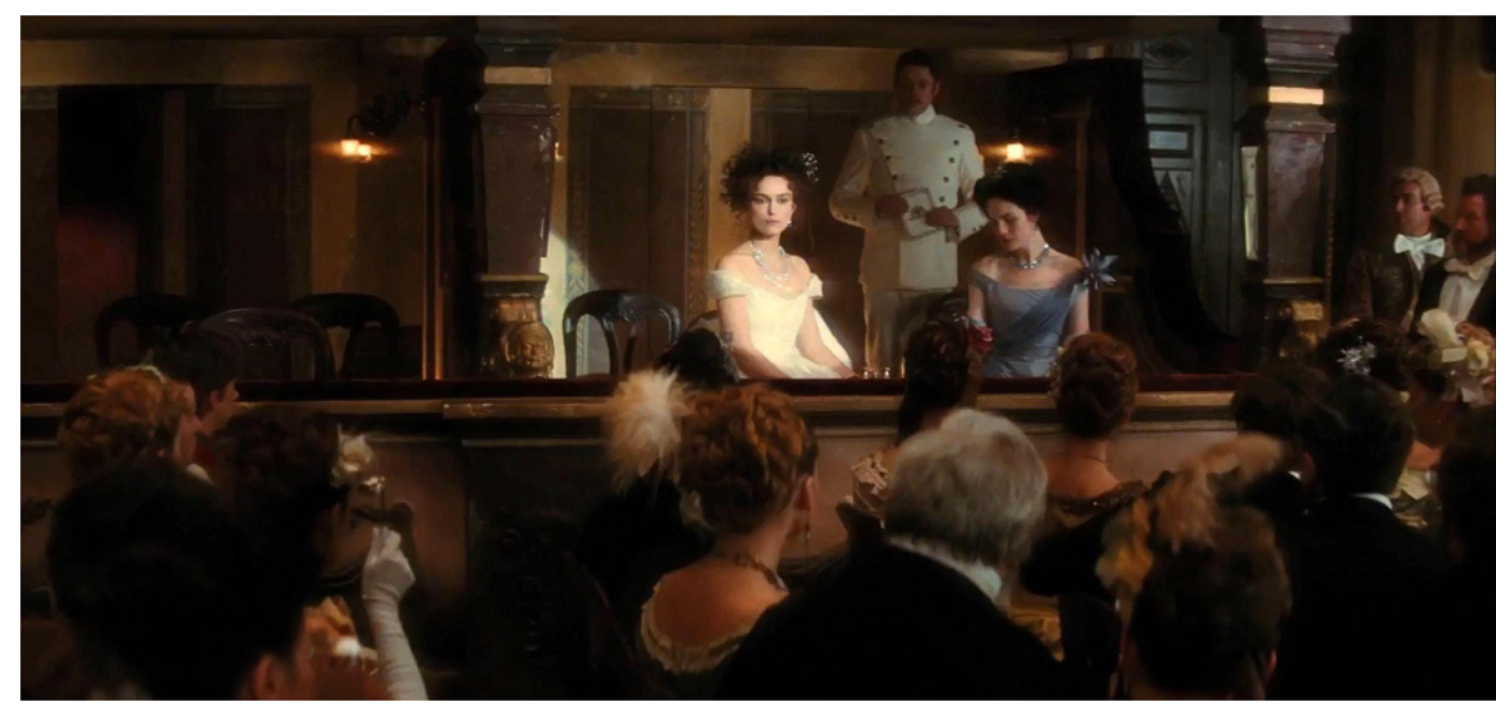

Figura 8: Cena da reprovação social 


\section{Último ato - 0 nível mítico}

Percebemos que, no nível mítico, a narrativa das marcas de moda foi uma referência fundamental para a construção simbólica do figurino cinematográfico em Anna Karenina.

O modelo de Anna Karenina usa das referências do século XVIII, mas numa releitura modernizada que a aproxima do público contemporâneo para aludir à sofisticação e à feminilidade da personagem. $\mathrm{O}$ new look Dior é agenciado como manifesto do luxo e do poder de sedução, trazendo à tona o movimento e a sensualidade que um figurino histórico do século XVIII não poderia proporcionar. $O$ híbrido entre essas duas referências alude a dois mitos que dialogam e reforçam suas identidades criando possibilidades de vínculos com o espectador/consumidor. O objetivo da criação de figurino não seria, portanto a veracidade histórica dos trajes, mas algo que produzisse um efeito de sentido funcional ao desenvolvimento da narrativa, em diálogo com os esquemas interpretativos de um potencial público consumidor da película.

O colar utilizado por Anna Karenina nas duas cenas é da marca Chanel (ver figura 5), construindo outro dialogo mítico no qual a sensualidade, sofisticação e a força do universo feminino são reforçados pela personagem, seu figurino e a marca como legitimadora do look enquanto expressão do eu no contexto da cena.

O reforço das referências de Dior e Chanel é conscientemente agenciado para dotar de valores específicos associados às marcas o caráter da personagem por meio do figurino.

\section{Considerações finais}

Com o objetivo de mapear códigos do vestuário, este estudo propõe mais uma forma de ver e perceber a moda como elemento da narrativa e re/ des(construção) simbólica num processo de metalinguagem onde o filme, que é narrativa, é suportado pelo vestuário que é uma narrativa dentro da narrativa e que vai, num processo de massificação, ser suporte de narrativa pra construção das identidades em processo interno/coletivo da audiência transferindo significados para marcas e recebendo significação dos mesmos.

A indústria cinematográfica pode ser considerada hoje uma instância fundamental de criação e disseminação de valores éticos e estéticos. Sua aproximação cada vez maior com o universo da moda apenas reforça esse lugar estratégico, ao mesmo tempo em que fortalece o simbolismo das marcas em questão. A marca representada pelo diretor Joe Wright e sua equipe de produção, consagrada pelo requinte visual e cenográfico de suas produções, bem como a persona feminina de Keira Knightley, que vem se consolidando como imagem mítica associada à conquista da autonomia feminina na busca pelo amor romântico, são elementos simbólicos que, por si só, já permitem estabelecer um diálogo harmonioso com as narrativas de marca de moda agenciadas que, por sua vez, suplementam a construção simbólica da personagem.

Por outro lado, marcas contemporâneas utilizam o universo simbólico do Cinema como ferramenta poderosa de atração sobre uma ou outra direção estética, gerando o que se chama de tendência. Produtos são providos de significado na sociedade; o estudo do simbólico reside em entender como as pessoas compõem o seu próprio conceito e compram ou rejeitam produtos que as identifiquem com a forma idealizada, impulsionadas por seus significados. 


\section{Bibliografia}

BENJAMIN, Walter. Obras escolhidas: magia e técnica, arte e política. 7. ed. São Paulo: Brasiliense, 1994.

BLUMER, $H$. Fashion: from class differentiation to collective selection. Sociological quartely, Vol. 10 Summer 1969.

COSTA, F.A. de; O figurino como elemento essencial da narrativa. Famecos: Sessões do Imaginário. Porto Alegre, n.8, p. 38-41, ago. 2002.

DICHTER, E. Why we dress the way we do in The psychology of fashion Ed. Michael R.Solomon, USA: Lexington Books, 1985.

DONDIS, Donis A. Sintaxe da Linguagem Visual. São Paulo, Martins Fontes, 1997.

DURRAN, Jacqueline. Meet the woman behind Keira Knightley's Anna Karenina costumes: Jacqueline Durran. The Fashion Spot. 14 nov. 2012. Entrevista a Jennifer Davidson. Disponível em: http:// www.thefashionspot.com/runway-news/177335-meet-the-woman-behind-keira-knightlys-anna-karenina-costumes-jacqueline-durran/ Acesso em: 16 dez. 2013

DURRAN, Jacqueline. An interview with Oscar-winning costume designer Jacqueline Durran. Huffington Post. 26 fev. 2013. Entrevista a Mary Hall. Disponível em: http://www.huffingtonpost.com/ mary-hall/jacqueline-durran-best-costume-design-oscars_b_2762016.html Acesso em: 16 dez. 2013.

ECO, Umberto. Apocalípticos e integrados. 6. ed. São Paulo: Perspectiva, 2001.

ENGLIS, B. G.; SOLOMON M. R.; ASHMORE R. $D$. Beauty before the eyes of beholders: the cultural encoding of beauty types in magazine advertising and music television. Journal of advertising. Vol. XXIII, June 1994.

FORSYTHE, S. M.; DRAKE, M. F.; HOGAN, J. H. Influence of clothing attributes on the perception of personal characteristics. in The psychology of fashion Ed. Michael R. Solomon, USA: Lexington Books, 1985.

JULLIER, Laurent; MARIE, Michel. Lendo as imagens do cinema. São Paulo: Senac, 2012.

KOURLAS, Gia. Making words dance on screen. The New York Times. Nova York, p. C1, 24 nov. 2012.
LÉVI-STRAUSS, C. O pensamento selvagem. São Paulo: Editora Nacional e Editora da USP. 1970.

LIPOVETSKY, G. O império do efêmero: a moda e o seu destino nas sociedade modernas. São Paulo: Companhia das letras, 1989.

LURIE, A. A linguagem das roupas. Rio de Janeiro: Rocco, 1997.

MACIEL, E. J. C. ; MIRANDA, A. P. C. de . DNA da Imagem de Moda. In: V Colóquio Nacional de Moda, 2009, Recife. Anais do V Colóquio Nacional de Moda, 2009.

PENN, Gemma. Análise semiótica de imagens paradas. In: BAUER, Martin; GASKELL, George. Pesquisa qualitativa com texto, imagem e som: um manual prático. 5.ed. Petrópolis: Vozes, 2002. P. 319-342.

SIMMEL, G. Fashion. International Quartely October, 1904.

SOLOMON, M. R.; Consumer behavior: buying, having, and being. 3. Ed Massachusetts:. Prentice-Hall, Inc. New-Jersey. 1996.

SPROLES, G. B. Behavioral science theories of fashion in The psychology of fashion Ed. Michael R. Solomon, USA: Lexington Books, 1985.

THOMPSON, C. J.; Caring consumers: Gendered consumption meanings and the juggling lifestyle. Journal of Consumer Research. Vol. 22 March, 1996.

WRIGHT, Joe. Anna Karenina. [Filme]. Produção anglo-americana dirigida por Joe Wright. 129 min. color. son.

1 Universidade Federal de Pernambuco, Doutor em Comunicação pela Universidade Federal Fluminense. Cntato: amilcar.bezerra@gmail.com

2 Universidade Federal de Pernambuco, Doutora em Administração pela Universidade de São Paulo.

3 Para Umberto Eco, a definição de mito consiste na "simbolização incônscia, identificação do objeto com uma soma de finalidades nem sempre racionalizáveis, projeção na imagem de tendências, aspirações e temores particularmente emergentes num indivíduo, numa comunidade ou em toda uma época histórica." (ECO, 1964, p. 239) 